\title{
AN EXPERIMENTAL OBSERVATION RELATED TO THE PORE SPACE BETWEEN PARTICLES OF CEMENT IN PASTES AT EARLY AGES
}

Hamlin M. Jennings

Civil Engineering, Materials Science and Engineering, Northwestern University, Evanston, I11. 60208

Cement paste of water:cement ratios less than about 0.3 usually are not workable, but workability can be maintained at these lower water:cement ratios by using superplasticizers. A typical explanation [1] of the mechanism behind the effectiveness of superplasticizers is that they adsorb on the surface of cement particles and adjust the surface charge so that the particles become deflocculated. The individual particles flow more easily than larger flocs.

This note describes the result of a simple experiment that may be interpreted as evidence that particles of cement can not become deflocculated at normal water:cement ratios, even in the presence of a superplasticizer. An alternate explanation of the role of superplasticizers, therefore, may be necessary.

A normal Type I portland cement was placed in a graduated cylinder and vibrated until no further change in volume was observed. By using $3.15 \mathrm{~g} / \mathrm{cc}$ as the density of cement, and by knowing the weight and volume of the cement in the cylinder, one can calculate the percent solids as 448 , and the percent air as $56 \%$. If the air is replaced with water, the paste would have a water:cement ratio of about 0.38 . This value varied only slightly from experiment to experiment, and does not depend strongly on density.

At any water:cement ratio less than 0.38 , the particles must be packed more efficiently than those in the vibrated cylinder. Since all the particles in the cylinder are touching nearest neighbors, it is probable that at water: cement ratios less than 0.38 most particles (or particle assemblages) are touching a nearest neighbor.

Most cements contain a large number of small particles [see, for example, 2] that are frequently on the surface of a few larger particles. Thus, the interparticle contact in a paste may be primarily between the larger particles, with small particles distributed throughout the remaining space and on surfaces. If this is so, the fluidity of cement paste with low water:cement ratios (with or without superplasticizer) is more likely a function of the sliding resistance of particles over one another than a function of deflocculation of the particulate system. If there is deflocculation, then it may be restricted to the smaller particles, and their removal from the surface of the larger particles may allow both the small and large particles to slide more easily. Superplasticizers may, then, influence primarily the distribution of small particles.

Experiments of Diamond [3] that were intended to determine the size of flocs did not produce sensible results, and this may be because there are no well defined flocs in normal cement pastes. The evidence supports the idea of deflocculation is valid only at high water:cement ratios.

\section{REFERENCES}

1. S. Mindess and J.F. Young, Concrete, Prentice-Ha11, New Jersey (1981).

2. B.J. Dalgleish, P.L. Pratt and E. Toulson, J.Mater. Sci., 17, (1982) 2199.

3. S. Diamond, personal communication (1985). 